\title{
Breast Cancer Awareness and Detection of Asymptomatic Cases Using Breast Palpation and Fine-needle Aspiration in Bafoussam, Cameroon
}

\author{
Tagne Simo Richard ${ }^{1}$, Lydiane C.C. Ndopwang ${ }^{1}$, Paul F. Seke Etet ${ }^{2,3}$, Armel H. \\ Nwabo Kamdje ${ }^{1}$, Halmata Mohamadou ${ }^{1}$, Telefo Phelix Bruno ${ }^{4}$, Charlette Nangue ${ }^{5}$
}

${ }^{1}$ Department of Biomedical Sciences, Faculty of Sciences, University of Ngaoundere, Ngaoundere, Cameroon. ${ }^{2}$ Center for Sustainable Health and Development, Garoua, Cameroon. ${ }^{3}$ Department of Physiological Sciences and Biochemistry, FMBS, University of Ngaoundere, Cameroon. ${ }^{4}$ Department of Biochemistry University of Dschang, Dschang, Cameroon. ${ }^{5}$ Anatomo- Cytopathology Laboratory, University Hospital Center of Yaounde, Yaounde, Cameroon.

\begin{abstract}
Background: Breast cancer, the deadliest cancer in women worldwide, is often diagnosed at late stage in Cameroon, with high mortality and dire socioeconomic consequences. We investigated the reasons for breast cancer late diagnosis in Cameroon. Methods: Women (412) were randomly recruited in various locations in the city of Bafoussam, West Region, Cameroon. They self-administered a questionnaire assessing breast cancer awareness. Then, they underwent breast palpation, followed by fine needle aspiration (FNA) when a nodule was found. Results: $65 \%$ of the study participants were above 30 years; $80.9 \%$ had at least a secondary education; 94.4\% had heard about breast cancer and the main source of information was the media (57.3\%). Most participants were either uninformed or ill-informed (up to 72\%) about breast cancer risk factors, signs, and screening methods, in particular breast self-examination (BSE). Of the 17 women with nodules and other suspect signs, only 6 accepted fine needle aspiration (FNA). Three of the 6 had malignant nodules indicative of Invasive ductal carcinoma low grade (one case) and high grade (2 cases). Conclusions: Women living in Bafoussam are poorly aware of breast cancer screening methods, in particular BSE, and of the importance of early detection. BSE followed by FNA in women with nodules is a simple, yet good screening method to improve early detection and reduce the burden of breast cancer.
\end{abstract}

Keywords: Woman- Breast cancer awareness- Breast Self-examination- Fine-needle Aspiration- Cameroon- Africa

\section{Introduction}

Breast cancer is the deadliest cancer in women worldwide, the second leading cause of death from cancer in women in developed countries, and the leading cause of death from cancer in low- and middle-income countries [1-3]. Established risk factors for breast cancer include advanced age, early menarche, late first pregnancy, nulliparity, personal or family history of breast cancer or precancerous lesions, hormonal treatment or history of OCP use, high alcohol consumption, obesity in menopaused women, exposure to ionizing radiation, and genetic predisposition [4-5]. Early detection of breast cancer in asymptomatic women through screening is aimed at reducing the incidence of the disease, its rate of mortality, and advanced stage-associated morbidity [4-6-8].

Unfortunately, in developing countries a high proportion of women are diagnosed only in advanced disease stages, leading to a poor prognosis [1-3]. Notably, in Africa, more than $70 \%$ of women diagnosed with breast cancer are already at stages III and IV, where median survival rates are reportedly less than five years, unlike stages I and II that have high survival rates [9-13]. While mammography screening programs are well-established and caused decreases in breast cancer mortality in

Corresponding Author:

Dr. Tagne Simo Richard

Department of Biomedical Sciences, Faculty of Science, University of Ngaoundere, Ngaoundere, Cameroon.

Email: rstagne@gmail.com 
developed countries, most cases of breast lumps are detected often accidentally in Cameroonian women, with an incidence of 35.25 per 100,000 women and a mortality rate of $48.12 \%$ [14-15]. Early reports showed that this was partly due to the lack of awareness about screening methods, with few women attending national screening programs when available [16-17]. Moreover, unfortunately, in our context mammography is still inaccessible to the majority of the population due to a small number of imaging centers, and because mammographic examinations are still expensive and beyond the financial possibilities of the average Cameroonian. It is necessary to rely on an inexpensive and easy to perform alternative screening method, thus adapted to our economic context, such as clinical breast examination (CBE), particularly considering that severe cases of high-grade breast cancer are more and more diagnosed in woman younger than 35 [9-14-15].

The aim of the present study was to contribute to the understanding of factors preventing the early diagnosis of breast cancer in our environment. We hypothesized that poor awareness about breast cancer, and its screening methods and signs were the major driver of late diagnosis of breast cancer in Cameroon. To verify this hypothesis, we administered a questionnaire to women randomly selected in Bafoussam, a Cameroonian semi-agricultural town (rain forest) of approximately 347,517 inhabitants that only has one pathology laboratory and one pathologist, and where breast cancer campaigns have been carried out, although sporadically in the recent decade. We assessed also the feasibility of an early detection of breast cancer by breast palpation followed by fine-needle aspiration (FNA) cytology in cases where nodules were detected. FNA is a relatively inexpensive technique for breast cancer detection in professional clinical settings, which also presents with the advantages of being less invasive, having wide applicability for palpable tumors, and allowing sampling of different areas of the lesion, increasing the reliability of breast cancer diagnosis [18-19].

\section{Materials and Methods}

\section{Participants and ethical considerations}

Our participants were 412 women randomly selected among the residents of the city of Bafoussam, West Region, Cameron. Signed informed consent was obtained from each participant at recruitment. Before analysis, data collected were anonymized to protect the privacy of participants.

All the procedures of the study were approved by the ethical committee of the Faculty of Medicine, University of Ngaoundere, and an authorization was obtained from the Regional Delegation of the Ministry of Health to recruit participants for this study.

\section{Study procedures}

From June to September 2017, a cross-sectional study was conducted in Bafoussam, where simple random sampling was used to recruit asymptomatic/healthy women in various locations in the city, including markets, churches, meetings and congresses, hospitals, and private residences. Women previously diagnosed with breast cancer and women undergoing unilateral or bilateral mastectomy were not included.

After being presented individually with study rationale and detailed information on procedures, each participant willing to join the study had to sign an informed consent form. Afterwards, she was given an appointment at Bafoussam Central Hospital for data collection. During data collection, participants were allowed 30-40 min to self-administer a questionnaire aimed at collecting participant's sociodemographic characteristics, and at assessing awareness about breast cancer and screening good practice. All patients underwent clinical breast examination performed by surgeon or gynaecologist at the gynecological service of the Central hospital of Bafoussam. The technique involved a thorough physical examination of the breast including visual inspection, checking for palpation of the breast, examination of the axillary lymph nodes and the features breast abnormalities such as breast lumps, lumpiness, changes in breast size, skin and nipple changes. The whole procedure required about $1 \mathrm{~h}$ per patient.

\section{Data collection}

Awareness about breast cancer and recommended screening methods was assessed using a questionnaire collecting the following information:

- Demographic characteristics like age, education, and occupation;

- Physiological factors with established risk potential in breast cancer context such as age (to assess whether age was advanced), age at first menarche (to determine early onset), and the presence and onset of menopause (late vs. early);

- As well as personal history and family-related factors such as parity (to distinguish nulliparous from multiparous), age at first [1-3] pregnancy (to determine whether it occurred late), history of breast feeding, history of exposure to ionizing radiation, history of hormonal treatment, history of OCP use, family history of breast cancer, and history of alcohol and tobacco consumption;

In addition, the questionnaire also included questions aimed at assessing:

- The awareness about the recommended screening methods for breast cancer early detection (breast selfexamination and mammography);

- And knowledge about commonly reported breast cancer symptoms like nipple discharge, change in skin appearance, change in breast size, the presence of breast masses, and inflamed axillary lymph nodes.

\section{Breast examination}

When a nodule was identified as well as its characteristics (site, number, consistency, size, mobility relative to deep skin and plans, painful or not) during clinical breast examination performed by surgeon or gynaecologist at the gynecological service of the Central hospital of Bafoussam, FNA was performed with the consent of the participant, using a $10 \mathrm{~mL}$ syringe with 
a 3-gauge needle, using standard clinical procedures. Each sample collected was mounted on a slide, processed for May-Grünwald Giemsa staining, and analyzed using bright-field microscopy (magnifications $4 x$ to $40 x$ ) at the Laboratory of Anatomo-Cytopathology of the University Hospital Center of Yaoundé. In case of cancer, Fisher's simplification of Black's nuclear grading scheme was used to determine the grade.

Instead, when nipple discharge occurred at examination, characteristics were determined and recorded as well (aspect, uni- or bilateral, uni- or multi-orificiel). Moreover, palpation of armpits was also performed to assess eventual axillary lymph node inflammation. The following characteristics of inflamed axillary lymph nodes were determined and recorded: number, size, and mobility relative to surrounding tissue.

\section{Statistical analysis}

Data was collected, organized, and presented as frequency distributions. Data analysis was performed using XLStat Version 2019. The $\chi 2$ test was used to compare proportions and correlations were determined between education, occupation, and breast cancer awareness. Statistical significance was set at $p<0.05$.

\section{Results}

\section{Sociodemographic information}

Table 1 summarizes the sociodemographic information of the study participants. Most of the study participants $(65 \%)$ were above 30 years old. More than $80.9 \%$ had at least a secondary education, of which $58 \%$ who ended their studies in secondary School and $22.8 \%$ who received a higher education (Table 1 ). The participants were housewives, students, teachers, health professional, business women, civil administrator, and informal sector workers. Together, housewives (30.3\%), students (26.7\%), and business women (14.6\%) represented $71.6 \%$ of study participants.

Table 1. Sociodemographic Characteristics of Participants

\begin{tabular}{llcc}
\hline Variables & & $\mathrm{N}$ & $\%$ \\
\hline Age (years) & $<30$ & 142 & 34.47 \\
& $\geq 30$ & 270 & 65.53 \\
Education & None & 17 & 4.1 \\
& Primary & 60 & 14.6 \\
& Secondary & 241 & 58.1 \\
& University & 94 & 22.8 \\
& Housewife & 125 & 30.3 \\
& Student & 110 & 26.7 \\
& Teacher & 20 & 4.9 \\
& Health professional & 16 & 3.9 \\
& Business woman & 60 & 14.6 \\
& Civil Administrator & 11 & 2.7 \\
& Other, informal sector & 70 & 17 \\
\hline
\end{tabular}

Awareness about breast cancer risk factors and early signs

Table 2 presents the distribution of participants according to their awareness about breast cancer risk factors and alarming signs, and their sources of information. Surprisingly, most participants (72\%) were not aware of breast cancer risk factors, and some participants supposed to be aware wrongly reported extended wearing of tight bra as a risk factor (11.9\%), as well as traditional breast massage (6.1\%) (Table 2). The study participants who had the right information about breast cancer risk factors mainly listed prolonged use of contraceptive pills (5.1\%), and genetic factors (4.9\%). The occurrence of nodules in the breast as an alarming sign of disease was mentioned by $50 \%$ of women, followed by pain $(12.6 \%$ ) (Table 2 ). About $25 \%$ of participants were not aware of any alarming sign. Media were the most common source of information $(57.3 \%)$, followed by friends (46.6\%), and health professionals (31\%) (Table 2). Correlations were observed between the awareness about risk factors and signs and both the education level $(\mathrm{r}=0.72, \mathrm{p}<0.001)$ and occupation $(\mathrm{r}=0.65, \mathrm{p}<0.001)$, as participants with at least secondary education and those exerting professions requiring higher education tended to have the highest awareness levels.

\section{Awareness about breast cancer screening}

Table 3 summarizes the screening methods listed by women and personal frequencies of screening reported. Most participants $(62.6 \%)$ were not aware that breast cancer could be detected early with screening methods (Table 3). The participants who knew that breast cancer can be detected early mainly mentioned breast selfexamination (BSE) (69.5\%) among the screening methods, with a lesser number of participants also aware of clinical examination (11.0\%), mammography $(9.7 \%)$, ultrasound (4.5\%), or other methods $(5.2 \%)$.

Instead, regarding the frequency of screening: $19.25 \%$ of the participants (56.6\% of participants aware) had never performed breast cancer screening; $6.5 \%$ (18.9\% of participants aware) performed breast cancer screening sometimes; and $6.3 \%$ (24.5\% of participants aware) performed breast cancer screening often (Table 3 ).

\section{Breast examination outcome}

Table 4 summarizes the results of clinical examination. All women were palpated. Although most women had normal breasts $(95.1 \%)$, the following were detected: nodules ( 17 cases, $4.1 \%$ of participants); inflamed axillary lymph nodes (one case, $0.2 \%$ of participants); umbilical nipple (one case); and nipple discharge (one case) (Table 4). Surprisingly, despite agreeing previously to the experimental procedure, participants with inflamed lymph nodes and breast discharge refused further analyses, and 11 participants with nodules refused needle aspiration. Table 5 presents the reasons presented by the participants to refuse needle aspiration or further examination.

The characteristics and cytological diagnosis of the punctured nodules of the 6 women who accepted fine needle aspiration are presented in Table 6 . Three nodules were benign, while the other 3 were diagnosed as invasive 
Table 2. Awareness about Breast Cancer Risk Factors and Clinical Signs

\begin{tabular}{llcc}
\hline Variables & & $\mathrm{N}$ & $\%$ \\
\hline Source of information & Media & 236 & 57.3 \\
& Friends & 192 & 46.6 \\
& Health professionals & 128 & 31 \\
& School & 49 & 12 \\
\multirow{3}{*}{ Risk factors } & None & 297 & 72 \\
& Extended wearing of tight bra & 49 & 11.9 \\
& Traditional breast massage & 6.1 \\
Signs & Prolonged use of OCP & 25 & 5.1 \\
& Genetic & 21 & 4.9 \\
& None & 20 & 25 \\
& Nodules & 103 & 50 \\
& Pain & 206 & 12.6 \\
& Change in breast appearance & 52 & 7 \\
\end{tabular}

Table 3. Screening Methods Cited by Women and Personal Frequency of Screening

\begin{tabular}{lccc}
\hline Variables & & $\mathrm{N}$ & $\%$ \\
\hline Screening method awareness & None & 258 & 62.6 \\
& Clinical Examination & 17 & 4.1 \\
& Mammography & 15 & 3.6 \\
& BSE $^{\text {a }}$ & 107 & 26 \\
& Ultrasound & 7 & 1.8 \\
Frequency of screening & Others & 8 & 1.9 \\
& Never & 81 & 19.6 \\
& Sometimes & 27 & 6.5 \\
\hline
\end{tabular}

${ }^{a}$ BSE, breast self-examination

Table 4. Results of Clinical Examination

\begin{tabular}{lcc}
\hline Variables & $\mathrm{N}$ & $\%$ \\
\hline Normal breasts & 392 & 95.1 \\
Nodules & 17 & 4.1 \\
Axillary lymph nodes & 1 & 0.2 \\
Umbilical nipple & 1 & 0.2 \\
Nipple discharge & 1 & 0.2 \\
\hline
\end{tabular}

ductal carcinoma (Black's simplified) grade I (one case) and grade II (two cases) (Table 6). The invasive ductal carcinoma grade I nodules were less than $2 \mathrm{~cm}$ large while grade II nodules were larger than $5 \mathrm{~cm}$ (Table 6).

\section{Discussion}

Our results suggest poor awareness about breast cancer screening methods, risk factors, and signs among women in the city of Bafoussam. This is surprising considering that most of the study participants were young women, had heard about breast cancer (94.5\%), and had the right education level to access more information $(80.9 \% \mathrm{had}$ at least secondary education). This finding could be explained by difficult access to good information and population poor awareness about the importance of early detection, as the main sources of information were the media (57.3\%) and friends (46.6\%). Similar findings were reports in various other African countries [20-22]. Information coming from the entourage is often wrong or incomplete, which can explain why $42.61 \%$ of responding participants listed the wearing of tight bra and traditional breast massage as a risk factors for developing the disease and why only 11 over the 17 participants with alarming signs underestimated the importance to confirm or rule out breast cancer diagnosis. Besides, only $12 \%$ of the study participants were informed about breast cancer and its signs and risks by their schools, which is surprising for a study population where $26.7 \%$ are students, suggesting that schools are not informing their students enough about breast cancer. Nonetheless, in our study $49 \%$ of participants were aware that breast cancer can be prevented by early detection with nodules as a major sign, against $95 \%$ in studies performed a decade ago in compared Cameroonian cities [17-23], which reflects the message of the sporadic national breast cancer awareness 
Table 5. Reasons Presented to Refuse Needle Aspiration or Further Examination

\begin{tabular}{lc}
\hline Reasons & $\mathrm{N}$ \\
\hline Participants claimed to lack time for additional tests & 2 \\
Participants claimed that they didn’t feel pain, so they did not need FNA a & 4 \\
Participants claimed that their family doctors told them not to worry about the finding, so they did not need FNA & 2 \\
$\begin{array}{l}\text { Participants claimed that should it be breast cancer it could only result from witchcraft, and thus, they would not } \\
\text { need hospitals to deal with it }\end{array}$ & 2 \\
«I prefer to stay with my lump without knowing if it is cancer or not » & 3
\end{tabular}

${ }^{a}$ FNA, fine needle aspiration

Table 6. Characteristics of Punctured Nodules

\begin{tabular}{|c|c|c|c|c|c|c|}
\hline & Nodule 1 & Nodule 2 & Nodule 3 & Nodule 4 & Nodule 5 & Nodule 6 \\
\hline Site & $\begin{array}{l}\text { Right internal } \\
\text { inferior quadrant }\end{array}$ & $\begin{array}{c}\text { Upper left } \\
\text { outer quadrant }\end{array}$ & $\begin{array}{c}\text { Upper right } \\
\text { outer quadrant }\end{array}$ & $\begin{array}{l}\text { Left internal } \\
\text { inferior quadrant }\end{array}$ & $\begin{array}{c}\text { Between outer superior } \\
\text { and right outer inferior } \\
\text { quadrants }\end{array}$ & $\begin{array}{l}\text { Under right } \\
\text { nipple }\end{array}$ \\
\hline Size $\left(\mathrm{cm}^{2}\right)$ & $2 \times 1$ & $3 \times 2$ & $7 \times 7$ & $1 \times 1$ & $10 \times 9$ & $8 \times 6$ \\
\hline Skin & Normal & Normal & Tough & Normal & Orange peel & Dark \\
\hline Mobility & Mobile & Mobile & Mobile & Mobile & Mobile & Mobile \\
\hline Pain & Absent & Absent & Present & Absent & Absent & Absent \\
\hline Consistency & Elastic & Elastic & Firm & Tough & Tough & Tough \\
\hline Nipple discharge & Absent & Absent & Absent & Absent & Absent & Absent \\
\hline Inflamed ALN a & Absent & Absent & Absent & Absent & Absent & Absent \\
\hline Cytology & \multicolumn{2}{|c|}{ Fibroadenoma } & Galactophoric cyst & \multicolumn{2}{|c|}{ Grade II IDCbs ${ }^{b}$} & grade I IDCbs \\
\hline
\end{tabular}

${ }^{a}$ ALN, Axillary lymph nodes. ${ }^{\text {b }}$ IDCbs, Invasive ductal carcinoma of Black simplified

campaigns of the last decade and suggests that they had a positive impact. Moreover, a significant correlation was found between professional occupation, level of education, and awareness about risk factors and signs of breast cancer, with nodules in the breast as the best-known sign $(50 \%)$, corroborating various reports in other African countries [20-22], and indicating that the message of the awareness campaigns was not easily accessible to uneducated public. Thus, the poor awareness about breast cancer screening methods and signs may be due to poor communication with the public. Notably, as observed in Morocco, where sensitization of women to BSE increased the early diagnosis of breast cancer from $56.4 \%$ in 2004 to $68.5 \%$ in 2009 [4-21], increasing breast cancer awareness level, in particular with information on screening methods and on the importance of early detection could further improve the health seeking behavior of women and cancer early detection rates in Cameroon, and beyond. Weak practice of BSE was reported in various countries in Africa, including for instance, Nigeria, Togo, Tunisia, and Morocco, with practice rate ranging between $11.6 \%$ and 34.9\% [4-9-11-14-15-21-24].

As in earlier studies aimed at showing that FNA can be used as first-line for breast cancer diagnosis in countries with limited resources [18-19-25], FNA cytological examination allowed reliable diagnosis and classification of breast cancer in our study. FNA can be performed even in basic health facilities, only requires trained staff, and processed samples can easily be routed to health facilities with a pathologist for analysis. Unfortunately, our findings add to the growing evidence supporting that high-grade cancer is more and more diagnosed in young women in West Africa [10-12-15-20-22-24]. The discovery of breast cancer at Stage III observed in our study exposes patients to long, expensive, and aggressive treatment, with low chances of good therapeutic outcome. Notably, the two cases with aggressive cancer were among the 6 participants with alarming signs who accepted to undergo further testing, over the 17 detected. Most of the women who refused additional tests were unaware of the existence of asymptomatic phases of breast cancer and of the importance of early detection, further emphasizing on the importance of improving awareness campaign number and quality. Such refusal based on ignorance clearly contributes to late detection of breast cancer in Africa.

Overall, our findings emphasize the need to raise awareness and provide the right information to the public at a large scale for early detection of breast cancer, by introducing, for instance, Information, Education and Communication (IEC)-based approaches to schools and hospitals, as well as advertising in public places, in addition to classical media. Our data also support that fine needle aspiration of nodules provides reliable diagnosis of tumors and is feasible in remote areas, once the staff is trained.

\section{Acknowledgements}

Authors thank the authorities and the health professionals of Bafoussam Central Hospital for their help in data collection.

\section{Funding statement}

The present study was partly funded by 
the Department of Biomedical Sciences, Faculty of Science, University of Ngaoundere, Ngaoundere, Cameroon.

\section{References}

1. Ahmad A. Breast Cancer Statistics: Recent Trends. Adv Exp Med Biol. 2019;1152:1-7.

2. Azubuike SO, Muirhead C, Hayes L, McNally R. Rising global burden of breast cancer: the case of sub-Saharan Africa (with emphasis on Nigeria) and implications for regional development: a review. World J Surg Oncol [Internet]. 22 mars 2018 [cité 29 déc 2019];16. Disponible sur: https:// www.ncbi.nlm.nih.gov/pmc/articles/PMC5863808/

3. Maajani K, Jalali A, Alipour S, Khodadost M, Tohidinik HR, Yazdani K. The Global and Regional Survival Rate of Women With Breast Cancer: A Systematic Review and Metaanalysis. Clin Breast Cancer. 2019;19(3):165-77.

4. Kolak A, Kamińska M, Sygit K, Budny A, Surdyka D, Kukiełka-Budny B, et al. Primary and secondary prevention of breast cancer. Ann Agric Environ Med. 23 déc 2017;24(4):549-53.

5. Wood ME, Rehman HT, Bedrosian I. Importance of family history and indications for genetic testing. Breast J. 2020;26(1):100-4.

6. Colditz GA, Bohlke K. Priorities for the primary prevention of breast cancer. CA Cancer J Clin. juin 2014;64(3):186-94.

7. Dubey AK, Gupta U, Jain S. Breast Cancer Statistics and Prediction Methodology: A Systematic Review and Analysis. Asian Pacific Journal of Cancer Prevention. 3 juin 2015;16(10):4237-45.

8. Scheideler JK, Klein WMP. Awareness of the Link between Alcohol Consumption and Cancer across the World: A Review. Cancer Epidemiol Biomarkers Prev. 2018;27(4):429-37.

9. Adedokun B, Zheng Y, Ndom P, Gakwaya A, Makumbi T, Zhou AY, et al. Prevalence of Inherited Mutations in Breast Cancer Predisposition Genes among Uganda and Cameroon Women. Cancer Epidemiol Biomarkers Prev [Internet]. 1 janv 2019 [cité 16 mars 2020]; Disponible sur: https:// cebp.aacrjournals.org/content/early/2019/12/21/1055-9965. EPI-19-0506

10. Elamin A, Ibrahim ME, Abuidris D, Mohamed KEH, Mohammed SI. Part I: cancer in Sudan-burden, distribution, and trends breast, gynecological, and prostate cancers. Cancer Med. mars 2015;4(3):447-56.

11. Lukong KE, Ogunbolude Y, Kamdem JP. Breast cancer in Africa: prevalence, treatment options, herbal medicines, and socioeconomic determinants. Breast Cancer Res Treat. nov 2017;166(2):351-65.

12. Muliira RS, Salas AS, O'Brien B. Quality of Life among Female Cancer Survivors in Africa: An Integrative Literature Review. Asia Pac J Oncol Nurs. mars 2017;4(1):6-17.

13. Olayide AS, Halimat AJ, Samuel OA, Ganiyu RA, Soliu OA. Level of awareness and knowledge of breast cancer in Nigeria. A systematic review. Ethiop J Health Sci. 15 mars 2017;27(2):163.

14. Azemfac K, Christie SA, Carvalho MM, Nana T, Fonje AN, Halle-Ekane G, et al. A Community-Based Assessment of Knowledge and Practice of Breast Self-Examination and Prevalence of Breast Disease in Southwest Cameroon. J Cancer Epidemiol. 2019;2019:2928901.

15. Sama C-B, Dzekem B, Kehbila J, Ekabe CJ, Vofo B, Abua $\mathrm{NL}$, et al. Awareness of breast cancer and breast selfexamination among female undergraduate students in a higher teachers training college in Cameroon. Pan Afr Med
J. 2017;28:91.

16. Nde FP, Assob JCN, Kwenti TE, Njunda AL, Tainenbe TRG. Knowledge, attitude and practice of breast self-examination among female undergraduate students in the University of Buea. BMC Res Notes. 15 févr 2015;8:43.

17. Suh MAB, Atashili J, Fuh EA, Eta VA. Breast selfexamination and breast cancer awareness in women in developing countries: a survey of women in Buea, Cameroon. BMC Res Notes. 9 nov 2012;5:627.

18. Dinas K, Pratilas GC, Nasioutziki M, Vavoulidis E, Makris V, Loufopoulos PD, et al. Clinical Significance of Fine Needle Aspiration in Managing Patients with Breast Lesions. Folia Medica. 1 sept 2018;60(3):364-72.

19. Wang M, He X, Chang Y, Sun G, Thabane L. A sensitivity and specificity comparison of fine needle aspiration cytology and core needle biopsy in evaluation of suspicious breast lesions: A systematic review and meta-analysis. Breast. févr 2017;31:157-66.

20. Agbokey F, Kudzawu E, Dzodzomenyo M, Ae-Ngibise KA, Owusu-Agyei S, Asante KP. Knowledge and Health Seeking Behaviour of Breast Cancer Patients in Ghana. International Journal of Breast Cancer. 1 avr 2019;2019:1-9.

21. Charaka H, Khalis M, Elfakir S, Huybrechts I, Khazraji YC, Lyoussi B, et al. Knowledge, Perceptions, and Satisfaction of Moroccan Women Towards a New Breast Cancer Screening Program in Morocco. J Cancer Educ. 24 déc 2019;

22. Oluwatosin OA, Oladepo O. Knowledge of breast cancer and its early detection measures among rural women in Akinyele Local Government Area, Ibadan, Nigeria. BMC Cancer. déc 2006;6(1):271.

23. Price AJ, Ndom P, Atenguena E, Mambou Nouemssi JP, Ryder RW. Cancer care challenges in developing countries. Cancer. 15 juill 2012;118(14):3627-35.

24. Gueye SMK, Bawa KDD, Ba MG, Mendes V, Toure CT, Moreau JC. [Breast cancer screening in Dakar: knowledge and practice of breast self examination among a female population in Senegal]. Rev Med Brux. avr 2009;30(2):77-82.

25. Mohammed AZ, Edino ST, Ochicha O, Alhassan SU. Value of Fine Needle Aspiration Biopsy in Preoperative Diagnosis of Palpable Breast Lumps in Resource-Poor Countries: A Nigerian Experience. 31 Déc 2005 [Cité 16 Mars 2020]; Disponible Sur: Https://Tspace.Library.Utoronto.Ca/ Handle/1807/5042.

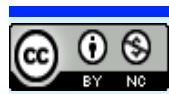

This work is licensed under a Creative Commons AttributionNon Commercial 4.0 International License. 